\title{
COUNCIL MEETING: OPENING ADDRESS
}

\section{SOME COMMENTS ON THE HEALTH-CARE PROFESSION IN THE NEW SOUTH AFRICA}

\section{Professor S A Strauss}

Thank you for the honour you have done me to invite me to come and say a few words to you on this occasion.

I intend giving you a few thoughts on the health-care profession in the new South Africa as it may be shaped by developments in the legal and constitutional field.

Some weeks ago I was asked by a group of doctors to talk on this topic. When I had concluded a fairly lengthy address and question time arrived, there was a deafening silence, which I found quite unusual. The chairman repeated his invitation for questions, and a single questioner stepped forward, with a single question: "How far is Canada from South Africa?" And I thought I had given an optimistic, if at the same time realistic, appraisal from the point of view of a lawyer with more than a passing interest in medical practice and the legal problems surrounding medicine!

If I were to sum up in a single sentence the present socio-economic character of our system of medical and health care services, I would say this: What we have today is largely the product of a policy of laissez-faire, with a good deal of legislative interference. The end-result is that although the practice of medicine (and I include physiotherapy and other health care professions) is typically that of a capitalist society, in a state which has applied socialist policies in respect of certain sectors - we do not have an entirely free-market system or an entirely socialist system. Nor do we have a national health service.

Put in positive terms, what we do have is the following:

- Privately practising health-care workers are legally speaking free contractors - except when it comes to fees, which are legislatively controlled for the majority of practitioners, by

- the Medical and Dental Act 56 of 1974 (section 53) which gives the South African Medical and Dental Council the jurisdiction to decide what fee charged by a practitioner registered under the Act is reasonable, and

- the Medical Schemes Act of 1967, section 29, whereby a scale of benefits is promulgated for doctors and some other professional groups.

It may therefore be said that there is a "socialist" element in fee-determination, in the sense that the practitioner is not free to charge any fee that he or she wishes, or that is agreed upon with the patient.

- The public sector is still the largest supplier of hospital services and perhaps also of medical services. But the role of the private sector is increasing rapidly, particularly in providing hospital services.

- Medical schemes have become a major and crucial factor over the past three to four decades in financing medical service. This, of course, is not a "socialist" but a capitalist feature, because the medical schemes are largely funded by their members who may require medical services.

Any attempt at describing in brief the socio-economic-political dynamics of our time will be controversial.

As I see it, the number one factor is a population explosion which has assumed huge proportions.

Secondly, there has been a change-over within a relatively short period of time from one model of social engineering to a completely different model.

Thirdly, over the last decade South Africa has experienced a gradual economic decline, the causes of which are manifold and some of which lie beyond our borders, or were otherwise beyond our control.

Fourthly - in the context of discussing the health-care professions - there has been an increasing sophistication in the nature, quality and range of medical services and medicines. This was a development that went hand in hand with some of these services and goods becoming more and more expensive - regrettably at a time when productivity and per capita income have decreased

Now, looking into the crystal ball - and remember, it is the amateur fortune-teller speaking!

In line with what Confucius said: "The only thing which is certain, is that things will change."

On the positive side, there is a far greater willingness in our society today to accept the inevitability of change, and a desire to give positive direction (stukrag) to change.

On the negative side, I want to mention only three factors

- an underestimation by some of the importance of economic advancement,

- an unwillingness shown by some of our leaders to bury the hatchet and to forget and forgive past mistakes, and

- a tendency by some to think in terms of instant solutions, immediate Utopia, rather than gradualism and carefully prepared and executed development programmes which will benefit society as a whole in due course.

Taking an optimistic view of future constitutional trends, we may - with a good deal of luck - achieve a democratic system of government with a bill of rights, sooner or later. But its success can only be secured if the introduction goes hand in hand with social stability, which means self-discipline and a preparedness to work hard. Economic advancement and productivity will be the kingpin of a successful new South Africa. If this can be achieved (and it is a big IF) within the next decade or two, or even three, there will be a future for all of us and for our professions.

I, for one, foresee no Utopia for the health-care professions. The pressure on government for a national health service will probably become irresistible. Its cost will become a major debit against State finances. Other services will assume a lesser priority, especially renewal and expansion of infrastructure. In the health-care field, private practice will, nevertheless, remain a major component of health services.

The professions will probably be less rigidly regulated. That may be good news in a way, but the recognised professions will have to compete to a larger extent with "informal" health-care providers. Because of the escalating cost of "formal" medical services, there will also be a trend towards self-medication and self-treatment.

The medical schemes - already in difficulties - will face an increasing crisis in financing medical and hospital costs.

Many of us will have to work harder and be prepared to earn relatively less for the same work.

People in government will have to realise that any drastic interference with free-market forces, or over-taxing of health-care providers, may bring about a decline in quality and availability which will impact negatively on the training of the future generation of practitioners: in sum, the very viability of important branches of the profession will be at stake should there be any attempt at steering our economic system towards the ill-fated Marxist model.

But I am not going to end this brief talk on a doomsday note.

As I see it, there will be an ever-increasing demand for physiotherapists. A prominent personality has been reported in the press as saying that 80 percent of the population does not know about 
physiotherapy. I, myself, and members of my immediate circle of relatives and friends, have benefitted greatly from you science. So we certainly know about you!

Apart from alleviating pain, discomfort and misery, physiotherapy must undoubtedly, in the industrial society, contribute enormously to productivity. It must be one of the most cost-effective forms of medical treatment. I believe that statistical studies have been done in the USA and elsewhere which demonstrate this clearty. Perhaps one of you will be so good as to furnish me with the results of such a study.

Let me conclude with a statement of faith: It is my belief that there is a sufficiently large body of well-meaning, hardworking idealists and talented people in this country to see us through a phase of our history which is critical, but at the same time most challenging. 